\title{
ORIGINAL
}

\section{Conservative oxygen therapy for mechanically ventilated adults with sepsis: a post hoc analysis of data from the intensive care unit randomized trial comparing two approaches to oxygen therapy (ICU-ROX)}

Paul Young ${ }^{1,2^{*}} \mathbb{D}$, Diane Mackle ${ }^{1}$, Rinaldo Bellomo ${ }^{3,4,5,6}$, Michael Bailey ${ }^{3,5}$, Richard Beasley ${ }^{1}$, Adam Deane ${ }^{5,6}$, Glenn Eastwood ${ }^{3,4}$, Simon Finfer ${ }^{7,8}$, Ross Freebairn ${ }^{9}$, Victoria King ${ }^{3}$, Natalie Linke ${ }^{3}$, Edward Litton ${ }^{10}$, Colin McArthur 1,11, Shay McGuinness ${ }^{1,12}$, Rakshit Panwar ${ }^{13,14}$ and the ICU-ROX Investigators the Australian New Zealand Intensive Care Society Clinical Trials Group

(0) 2019 Springer-Verlag GmbH Germany, part of Springer Nature

\begin{abstract}
Purpose: Sepsis is a common reason for intensive care unit (ICU) admission and mortality in ICU patients. Despite increasing interest in treatment strategies limiting oxygen exposure in ICU patients, no trials have compared conservative vs. usual oxygen in patients with sepsis.

Methods: We undertook a post hoc analysis of the 251 patients with sepsis enrolled in a trial that compared conservative oxygen therapy with usual oxygen therapy in 1000 mechanically ventilated ICU patients. The primary end point for the current analysis was 90-day mortality. Key secondary outcomes were cause-specific mortality, ICU and hospital length of stay, ventilator-free days, vasopressor-free days, and the proportion of patients receiving renal replacement therapy in the ICU.

Results: Patients with sepsis allocated to conservative oxygen therapy spent less time in the ICU with an $\mathrm{SpO}_{2} \geq 97 \%$ (23.5 h [interquartile range (IQR) 8-70] vs. $47 \mathrm{~h}$ [IQR 11-93], absolute difference, 23 h; 95\% Cl 8-38), and more time receiving an $\mathrm{FiO}_{2}$ of 0.21 than patients allocated to usual oxygen therapy (20.5 h [IQR 1-79] vs. $0 \mathrm{~h}$ [IQR 0-10], absolute difference, 20 h; $95 \% \mathrm{Cl} 14-26$ ). At 90-days, 47 of 130 patients (36.2\%) assigned to conservative oxygen and 35 of 120 patients (29.2\%) assigned to usual oxygen had died (absolute difference, 7 percentage points; $95 \% \mathrm{Cl}-4.6$ to $18.6 \%$ points; $P=0.24$; interaction $P=0.35$ for sepsis vs. non-sepsis). There were no statistically significant differences between groups for secondary outcomes but point estimates of treatment effects consistently favored usual oxygen therapy.
\end{abstract}

\footnotetext{
*Correspondence: paul.young@ccdhb.org.nz

${ }^{2}$ Intensive Care Unit, Wellington Regional Hospital, Private Bag 7902 Wellington South, New Zealand

Full author information is available at the end of the article
}

A complete list of investigators in the intensive care unit randomized trial comparing two approaches to oxygen therapy (ICU-ROX) is provided in the electronic supplementary material.

\section{亚 Springer}


Conclusions: Point estimates for the treatment effect of conservative oxygen therapy on 90-day mortality raise the possibility of clinically important harm with this intervention in patients with sepsis; however, our post hoc analysis was not powered to detect the effects suggested and our data do not exclude clinically important benefit or harm from conservative oxygen therapy in this patient group.

Clinical Trials Registry: ICU-ROX Australian and New Zealand Clinical Trials Registry number ACTRN12615000957594.

Keywords: Sepsis, Septic shock, Oxygen therapy, Hyperoxia, Hyperoxaemia, Randomised controlled trials, Intensive care

\section{Introduction}

Sepsis is a common reason for intensive care unit (ICU) admission and mortality in ICU patients [1]. It causes or contributes to between one-third and one half of all deaths in hospital [2] and is responsible for more than six million deaths worldwide each year [3]. Critically ill patients with sepsis have high healthcare resource requirements [4]. Many ICU patients with sepsis require invasive ventilation and, among such ventilated patients, the provision of supplemental oxygen is ubiquitous. Yet, for patients with sepsis who require invasive mechanical ventilation, the most appropriate oxygen regimen is unknown [5].

A recent meta-analysis of randomized trials in acutely ill adults reported that liberal use of oxygen increased mortality compared with more restrictive approaches [6]. However, this analysis included only one (unpublished) randomized controlled trial (RCT) in patients with sepsis [7]. A second study which evaluated the effect of ventilation with a fraction of inspired oxygen $\left(\mathrm{FIO}_{2}\right)$ of 1.0 during the first $24 \mathrm{~h}$ of sepsis [8] was stopped early, when the intervention was associated with a non-significant increase in mortality.

We recently reported the findings of the intensive care unit randomized trial comparing two approaches to oxygen therapy (ICU-ROX) [9]. ICU-ROX compared conservative oxygen therapy with usual oxygen therapy in 1000 mechanically ventilated ICU patients. Despite a growing body of sepsis-related research [10], there are no published studies evaluating oxygen regimens in patients with sepsis. Given this limited evidence base, we undertook a post hoc exploratory analysis to evaluate the effect of conservative vs. usual oxygen therapy on 90-day mortality and other patient-centered outcomes in the subset of patients with sepsis at the time of recruitment to ICU-ROX. We conducted this analysis to provide data on important outcomes to guide the design, powering, and execution of a future trial to test the hypothesis that conservative oxygen therapy would reduce 90-day mortality compared with usual oxygen therapy in patients with sepsis.

\section{Take-home message}

In this post hoc analysis of patients with sepsis who were enrolled in ICU-ROX, conservative oxygen therapy did not result in a statistically significant decrease in 90-day mortality compared with usual oxygen therapy. The point estimates of treatment effect we observed suggest that the choice of oxygen regimen used in patients with sepsis could have a clinically important effect on mortality and that usual (liberal) oxygen therapy might be preferred in such patients.

\section{Methods}

\section{Trial design}

We conducted a post hoc analysis of patients who had sepsis at the time of enrolment in ICU-ROX. ICU-ROX was a 1000 participant, investigator-initiated, multicenter, prospective, parallel group, randomized clinical trial. The protocol [11] and primary analysis [9] of this trial have been published previously. ICU-ROX was approved by the ethics committee responsible for each participating institution. Written informed consent for enrollment, or consent to continue and to use patient data, was obtained from each patient or from a legal surrogate. Where a patient died before consent to continue could be obtained, data were included if allowed by local regulations and approved by the relevant ethics committee.

\section{Patients}

Patients included in ICU-ROX were mechanically ventilated adults aged $\geq 18$ years who were expected to remain mechanically ventilated in the ICU beyond the calendar day after recruitment were included in ICU-ROX. Randomization was required within $2 \mathrm{~h}$ of invasive mechanical ventilation and/or non-invasive ventilation in an ICU. Otherwise, patients were considered to have missed the enrolment window.

There were three ways for a patient to be defined as having sepsis: (1) having an explicit diagnosis of sepsis or septic shock recorded at baseline in the ICU-ROX database; (2) having an explicit diagnosis of infection in the ICU-ROX database; and (3) having an admission diagnostic subcode for infection in the Australian and New Zealand Intensive Care Society Adult Patient Database 
[1]. The diagnostic codes and subcodes that were considered as infection-related are described in the electronic supplementary material (ESM).

While we did not prospectively identify patients who had organ dysfunction at baseline, as required to fulfill the contemporary definition of sepsis [12], all patients were invasively mechanically ventilated at randomization. Accordingly, we submit that it is highly likely that all included patients had the requisite degree of organ dysfunction required to fulfill this definition. To provide some confirmatory data regarding the fidelity of our approach to defining sepsis, we used registry data obtained from trial participants during the first $24 \mathrm{~h}$ in ICU [13]. Such data allowed us to provide an estimate of the proportion of patients who had confirmed sepsis within $24 \mathrm{~h}$ of ICU admission.

\section{Randomization and study treatment}

Patients in ICU-ROX were randomly assigned to conservative oxygen therapy or usual oxygen therapy using a secure internet-based randomization interface. The allocation sequence was generated by the study statistician using computer-generated random numbers with variable block randomization in a 1:1 ratio stratified by center.

In both treatment groups, the monitored lower limit alarm for oxygen saturation measured by pulse oximetry $\left(\mathrm{SpO}_{2}\right)$ was set at $90 \%$ by default, but an alternative lower limit could be specified if clinically indicated. If an arterial blood gas showed a partial pressure of oxygen $\left(\mathrm{PaO}_{2}\right)<60 \mathrm{mmHg}$ or unacceptably low arterial oxygen saturation $\left(\mathrm{SaO}_{2}\right)$, the fraction of inspired oxygen $\left(\mathrm{FiO}_{2}\right)$ could be increased, irrespective of $\mathrm{SpO}_{2}$.

In patients assigned to conservative oxygen, the $\mathrm{FiO}_{2}$ was reduced as much as possible down to a minimum of 0.21 , whilst still maintaining the $\mathrm{SpO}_{2}$ above the acceptable lower limit. We sought to minimize exposure to $\mathrm{SpO}_{2} \geq 97 \%$ and hence minimize the risk of hyperoxemia in patients assigned to conservative oxygen using an upper $\mathrm{SpO}_{2}$ alarm limit set at $97 \%$. This upper limit $\mathrm{SpO}_{2}$ alarm was used whenever supplemental oxygen was administered in the ICU.

In patients assigned to usual oxygen, no specific measures limited $\mathrm{FiO}_{2}$ or $\mathrm{SpO}_{2}$ except that the use of upper alarm limits for $\mathrm{SpO}_{2}$ was prohibited and the use of $\mathrm{FiO}_{2}$ less than 0.3 during invasive ventilation was discouraged.

Patients received their assigned oxygen therapy strategy until discharge from the ICU or 28 days from randomization, whichever was sooner. Treatment assignment was not disclosed to participants or their families.

\section{Outcome measures}

The primary outcome for this analysis was 90-day mortality ascertained by contacting patients or their next of kin or by other means where necessary. Secondary outcomes were ICU, hospital, and 180-day mortality, cause-specific mortality, survival time, ICU and hospital length of stay, ventilator-free days, vasopressor-free days, and the proportion of patients treated with new onset renal replacement therapy in the ICU.

Cause-specific mortality was categorized using a previously described method [14]. We defined ventilator-free days as the total number of calendar days or part calendar days of unassisted breathing during the first 28 days after randomization; all patients who died by day 28 were assigned zero ventilator-free days [15]. Vasopressor-free days were defined in an analogous fashion.

\section{Statistical analysis}

The statistical analysis plan for ICU-ROX was reported before enrolment completion [11]. Whilst not pre-specified, the analysis reported here has been conducted in accordance with the original analysis plan. Our decision to specify 90 -day mortality as the primary end point for this analysis instead of ventilator-free days was based on an assessment that differences in 90-day mortality would more intuitively understood by clinicians. We reasoned that providing 95\% CIs around 90-day mortality treatment estimates would provide a more clinically relevant estimate of likely treatment effects. The decision to use 90-day mortality as the primary outcome for this analysis was made after the primary ICU-ROX analyses were completed, but in advance of conducting the post hoc sepsis analysis. The sample size for the current analysis was determined by the number of patients with sepsis enrolled in ICU-ROX. However, based on a 90-day mortality rate of $36.2 \%$ in conservative oxygen therapy patients, a sample of 250 provides $80 \%$ power to detect an absolute reduction in mortality of $15.9 \%$ points using a two-tailed test at alpha of 0.05 . Analyses were conducted on an intention-to-treat basis. We defined the intention-to-treat population as all enrolled patients except those who withdrew consent for use of data. We did not impute missing values.

For the primary analysis of 90-day mortality, we used an unadjusted Fisher's exact test for equal proportions and report frequency (percentage) per treatment group with an absolute difference, odds ratio, and associated 95\% confidence intervals. Other dichotomous end points were analyzed in the same fashion. We compared survival times using log-rank tests and present these as KaplanMeier curves and used a Cox proportional hazards model to calculate hazard ratios for survival. For continuous secondary outcomes, we used a Wilcoxon rank-sum test with differences between medians calculated using quantile regression employing a simplex algorithm with $95 \%$ confidence intervals $(\mathrm{CI})$ calculated using the inversion method [16]. 
Hierarchical multivariable analyses were performed for all mortality outcomes using logistic regression and for survival using a Cox proportional hazards model. These analyses incorporated adjustment for the independent covariates of age, gender, and APACHE II score, with patients nested in site and site treated as a random variable.

To establish if patients with sepsis had a different response to the oxygen therapy regimens tested, we divided the entire ICU-ROX study cohort into subgroups of patients with an ICU admission diagnosis of infection (those eligible for this study) and patients without an ICU admission diagnosis of infection. We then tested for heterogeneity between subgroups in 90-day mortality by fitting an interaction between treatment and subgroup.

Analyses for variables that were measured repeatedly such as $\mathrm{FIO}_{2}$ and time-weighted $\mathrm{PaO}_{2}$, were performed using mixed linear modeling (with each patient treated as a random effect) fitting main effect for treatment and time and an interaction between treatment and time to determine if groups behaved differently over time.

Analyses were conducted using SAS statistical software, version 9.4 (SAS Institute). Statistical significance was determined using a two-sided hypothesis test with an alpha of 0.05. All results of this post hoc analysis should be considered for hypothesis generating.

\section{Results}

\section{Patient characteristics}

From September 2015 through May 2018, we enrolled 1000 patients into ICU-ROX from 21 ICUs in Australia and New Zealand. There were 965 patients in the intention-to-treat population. A total of 251 met our diagnostic criteria for sepsis and were eligible for inclusion in the current analysis (Fig. 1). A total of 96 were included based on an explicit ICU admission diagnosis of sepsis or septic shock recorded in the ICU-ROX database, 149 were included based on an ICU admission diagnosis of infection recorded in the ICU-ROX database, and six were included based on a diagnostic subcode obtained from the Australian and New Zealand Intensive Care Society Adult Patient Database. Among the 251 patients identified as having sepsis, 130 were assigned to conservative oxygen and 121 were assigned to usual oxygen. 90-day mortality was not available for one patient assigned to usual oxygen who did not consent to follow up beyond hospital discharge. The study groups had similar characteristics at baseline (Table 1, Tables S1-S3, ESM).

\section{Oxygenation and process of care measures}

Patients allocated to conservative oxygen spent less time in the ICU with an $\mathrm{SpO}_{2} \geq 97 \%$ (23.5 $\mathrm{h}$ [interquartile range (IQR) 8-70] vs. $47 \mathrm{~h}$ [IQR 11-93], absolute difference, $23 \mathrm{~h}$; 95\% CI 8-38) and more time receiving an $\mathrm{FiO}_{2}$ of 0.21 than patients allocated to usual oxygen (20.5 h [IQR 1-79] vs. 0 h [IQR 0-10], absolute difference, $20 \mathrm{~h}$; 95\% CI 14-26). Patients allocated to conservative and usual oxygen therapy spent $2.8 \%$ of hours (IQR $0.0-5.5 \%$ ) and $1.0 \%$ of hours (IQR $0.3-1.8 \%$ ), respectively, with $\mathrm{SpO}_{2}$ less than $91 \%$. Patients allocated to conservative and usual oxygen therapy spent $0.3 \%$ of hours (IQR $0.0-1.3 \%$ ) and $0.0 \%$ of hours (IQR $0.0-1.4 \%$ ), respectively, with $\mathrm{SpO}_{2}$ less than $88 \%$ (Table S4, ESM). Mean $\mathrm{FiO}_{2}$ and time-weighted mean $\mathrm{PaO}_{2}$ during the first ten mechanical ventilation days are shown in Fig. 2 with both being statistically and significantly lower in the conservative oxygen group. Additional physiological descriptors and process of care measures are shown in Figs. S1, S2, and Table S5, ESM.

\section{Primary outcome}

A total of 47 of 130 patients (36.2\%) assigned to conservative oxygen and 35 of 120 patients (29.2\%) assigned to usual oxygen had died by 90 -day; absolute difference; 7.0 percentage points; $95 \% \mathrm{CI}-4.6-18.6 \%$ points; odds ratio 1.38; 95\% CI 0.81-2.34; $P=0.24$ ) (Table 2, Fig. 3).

\section{Secondary outcomes}

No statistically significant differences by treatment group were observed in any of the specified mortality end points. However, point estimates of treatment effect on mortality rates were higher in patients allocated to conservative oxygen at each time point. Cause-specific mortality by treatment group is shown in Table 2 .

There were no statistically significant differences between treatment groups for other secondary end points. However, point estimates of treatment effect consistently favored usual oxygen (Table 2).

\section{Interaction analysis}

There was no statistically significant heterogeneity in the effect of conservative oxygen vs. usual oxygen therapy on 90-day mortality in patients with vs. without sepsis $(P=0.35)$. The characteristics of patients with sepsis, who were included in this analysis and the characteristics of patients without sepsis are shown in Table S6, ESM. 


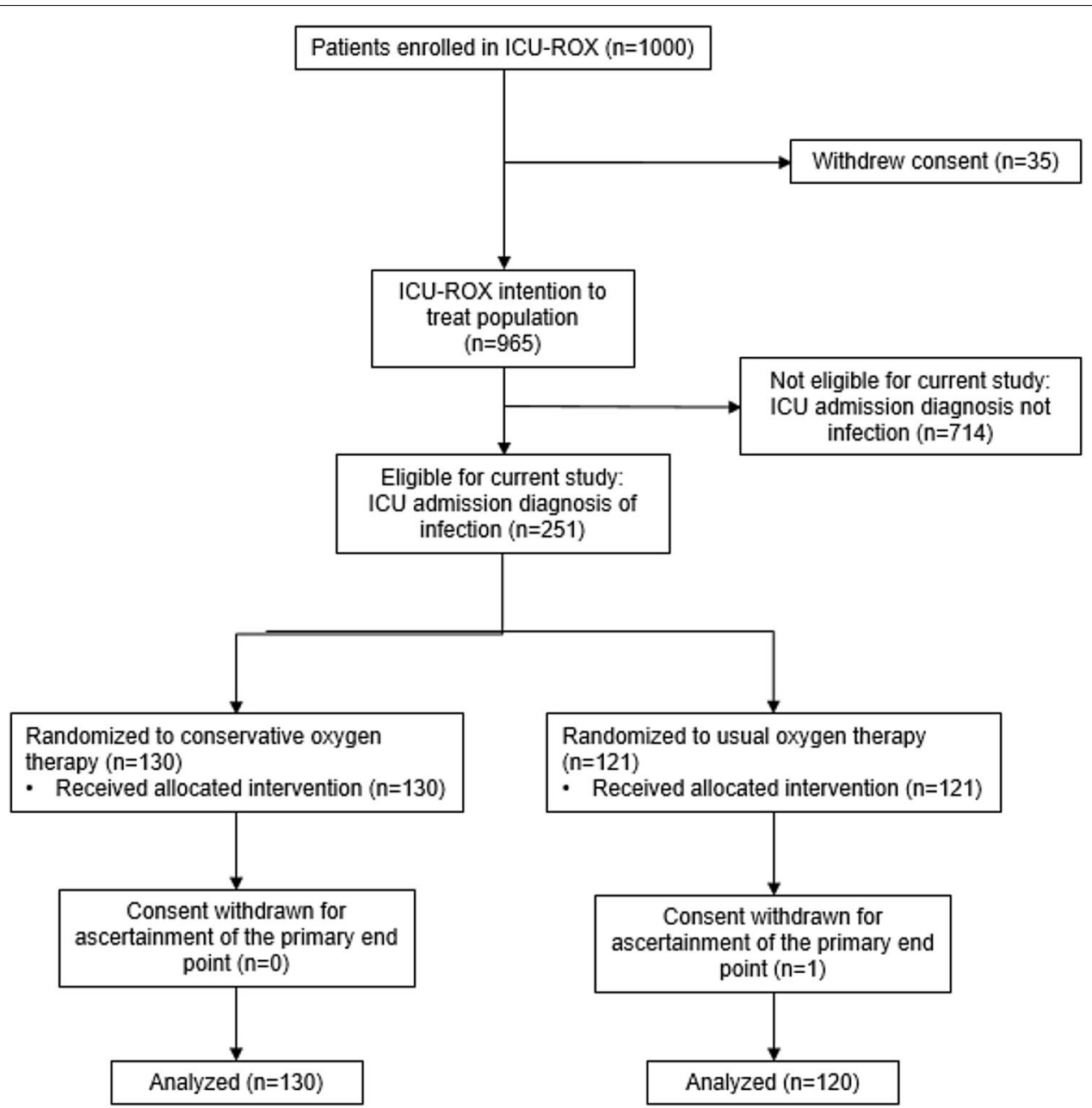

Fig. 1 Participant flow. ICU intensive care unit, ICU-ROX intensive care unit randomized trial comparing two approaches to oxygen therapy

\section{Discussion}

In this post hoc analysis of patients with sepsis who were enrolled in ICU-ROX, conservative oxygen therapy was not associated with a statistically significant decrease in 90-day mortality compared with usual oxygen therapy. While the point estimates of treatment effect we observed consistently favored a usual care (liberal) approach, the confidence intervals were wide indicating the need for larger trials to provide sufficiently robust data to generate clear clinical practice recommendations and guidelines.

The only previous RCT published evaluating oxygen regimens in patients with sepsis was the "Hyper2S" trial [8]. This trial evaluated therapeutic hyperoxemia and 3\% saline in a factorial design in patients with septic shock. It was terminated early because of a statistically significant increase in serious adverse events in the hyperoxemia group [8]. Although the difference was not statistically significant, the mortality rate at day 28 among patients assigned to hyperoxemia in this trial was eight percentage points higher than it was for patients assigned to normoxemia [8].

We conducted this analysis, because the findings of the Hyper2S trial had raised the possibility that patients with sepsis might be particularly susceptible to oxygen toxicity. We observed a 90-day mortality rate for patients treated with usual oxygen of seven percentage points lower than it was for patients who received conservative oxygen therapy. While not statistically significant, our results do not support those of the Hyper2S trial, which tested a very different oxygenation regimen. One possibility is that the adverse effects seen in the Hyper2S trial may not be seen with liberal oxygen regimens that do not mandate ventilation with $\mathrm{FiO}_{2}$ of 1 . 
Table 1 Characteristics of the patients at baseline*

\begin{tabular}{|c|c|c|}
\hline Characteristic & Conservative oxygen $(n=130)$ & Usual oxygen $(n=121)$ \\
\hline Age, years & $58.3 \pm 15$ & $57.2 \pm 14.3$ \\
\hline Male sex, $n(\%)$ & $75(57.7 \%)$ & $59(48.8 \%)$ \\
\hline \multicolumn{3}{|l|}{ Co-morbid conditions, $n$ (\%) } \\
\hline Respiratory & $5(3.8 \%)$ & $1(0.8 \%)$ \\
\hline Cardiovascular & $2(1.5 \%)$ & $0(0 \%)$ \\
\hline Hepatic & $4(3.1 \%)$ & $1(0.8 \%)$ \\
\hline Renal & $5(3.8 \%)$ & $1(0.8 \%)$ \\
\hline Immunosuppression by disease & $7(5.4 \%)$ & $9(7.4 \%)$ \\
\hline Immunosuppression by therapy & $19(14.6 \%)$ & $22(18.2 \%)$ \\
\hline Metastatic cancer & $2(1.5 \%)$ & $5(4.1 \%)$ \\
\hline \multicolumn{3}{|l|}{ Source of admission to ICU, $n(\%)$} \\
\hline Emergency department & $43(33.1 \%)$ & $50(41.3 \%)$ \\
\hline Hospital ward & $44(33.8 \%)$ & $34(28.1 \%)$ \\
\hline Transfer from another ICU & $2(1.5 \%)$ & $1(0.8 \%)$ \\
\hline Transfer from another hospital (except from another ICU) & $9(6.9 \%)$ & $12(9.9 \%)$ \\
\hline From OR following elective surgery & $1(0.8 \%)$ & $2(1.7 \%)$ \\
\hline From OR following emergency surgery & $31(23.8 \%)$ & $22(18.2 \%)$ \\
\hline Hours from initiation of invasive ventilation to randomization; median $[\mathrm{IQR}]^{\mathrm{a}}$ & $1.7[0.9-3.5]$ & $1.7[0.9-3.1]$ \\
\hline Hours from ICU admission to randomization; median [IQR] & $1.9[1.1-7.3]$ & $1.9[1.2-5.9]$ \\
\hline APACHE II score ${ }^{b}$ & $22.7 \pm 7.5$ & $22.8 \pm 8.2$ \\
\hline \multicolumn{3}{|l|}{ Physiology ${ }^{c}$} \\
\hline Temperature, ${ }^{\circ} \mathrm{C}$ & $36.8 \pm 1$ & $36.9 \pm 1.1$ \\
\hline Heart rate, beats per minute & $103 \pm 21.5$ & $104 \pm 21.3$ \\
\hline Mean arterial pressure, $\mathrm{mmHg}$ & $78.7 \pm 13.6$ & $79.2 \pm 13.9$ \\
\hline Mean airway pressure, $\mathrm{CmH}_{2} \mathrm{O}$ & $14.2 \pm 3.9$ & $12.6 \pm 3.5$ \\
\hline Respiratory rate, breaths per minute & $18.5 \pm 7.5$ & $17.6 \pm 5.2$ \\
\hline $\mathrm{SpO}_{2}, \%$ & $96.2 \pm 3$ & $95.9 \pm 3.7$ \\
\hline $\mathrm{PaO}_{2}, \mathrm{mmHg}$; median [IQR] & $97[77.5-161]$ & 99 [78.8-147] \\
\hline $\mathrm{PaO}_{2} / \mathrm{FiO}_{2}$ ratio, $\mathrm{mmHg}$ & $213 \pm 118$ & $200 \pm 102$ \\
\hline $\mathrm{PaCO}_{2}, \mathrm{mmHg}$ & $44.5 \pm 13.7$ & $44.3 \pm 11.1$ \\
\hline \multicolumn{3}{|l|}{ Physiological support $^{d}$} \\
\hline $\mathrm{FiO}_{2}$ & $0.65 \pm 0.24$ & $0.67 \pm 0.23$ \\
\hline PEEP, $\mathrm{cmH}_{2} \mathrm{O}$; median [IQR] & $8.3 \pm 3.1$ & $8.9 \pm 3.7$ \\
\hline Inotropic/vasopressor support, $n(\%)$ & $87(66.9 \%)$ & $85(70.2 \%)$ \\
\hline Renal replacement therapy, $n(\%)$ & $8(6.2 \%)$ & $4(3.3 \%)$ \\
\hline Fulfilled Sepsis 3.0 criteria within 24 h of ICU admission, $n$ (\%) & $125(96.2 \%)$ & $115(95 \%)$ \\
\hline
\end{tabular}

* Plus-minus values are expressed as mean $\pm \mathrm{SD}$

APACHE Acute Physiology And Chronic Health Evaluation, $I C U$ intensive care unit, $\mathrm{OR}$ operating room, $\mathrm{SpO}_{2}$ arterial oxygen saturation on pulse oximetry, $\mathrm{PaO} \mathrm{O}_{2}$ arterial partial pressure of oxygen, $\mathrm{FiO}_{2}$ fraction of inspired oxygen, $\mathrm{PaCO}_{2}$ arterial partial pressure of carbon dioxide, $P E E P$ positive end expiratory pressure

a Includes hours of ventilation prior to ICU admission

b Scores on the APACHE II range from 0 to 71, with higher scores indicating more severe disease and a higher risk of death

c Temperature data were available for 129 conservative oxygen patients and 120 usual oxygen patients; mean airway pressure data were available for 42 conservative oxygen patients and 36 usual oxygen patients; respiratory rate data were available for 130 conservative oxygen patients and 119 usual oxygen patients; $\mathrm{SpO}_{2}$ data were available for 129 conservative oxygen patients and 121 usual oxygen patients; $\mathrm{PaO}_{2} / \mathrm{FiO}_{2}$ ratio data were available for 125 conservative oxygen patients and 113 usual oxygen patients; and $\mathrm{PaCO}_{2}$ data were available for 125 conservative oxygen patients and 113 usual oxygen patients

d PEEP data were available for 128 conservative oxygen patients and 119 usual oxygen patients

Although we did not find a statistically significant interaction for the effect of usual oxygen on 90-day mortality for patients with vs. those without sepsis, we had limited power to detect such an interaction. Although our findings do not support our a priori hypothesis, there are plausible mechanisms by which using oxygen liberally 


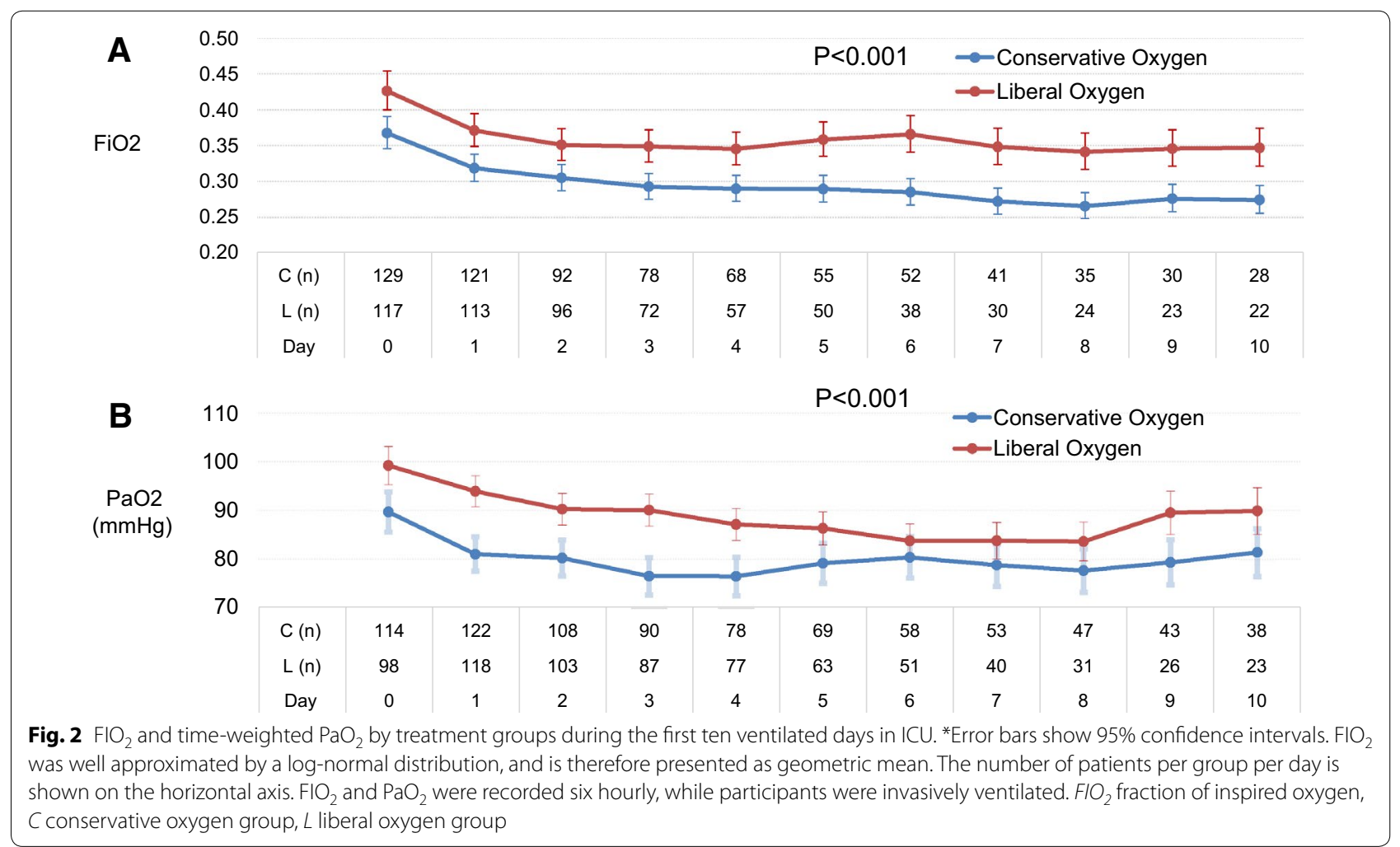

without targeting hyperoxemia might benefit patients with sepsis. The consequences of infections might be reduced directly with use of oxygen via enhanced oxidative killing of bacteria, and indirectly, for patients who have wounds, by enhancing wound healing through reepithelialization, blood vessel angiogenesis, and tissue collagen synthesis $[17,18]$. Experimental evidence suggests that oxygen tension is reduced in infected tissues compared with non-infected tissues [19]. Moreover, neutrophil superoxide production is enhanced in the presence of high oxygen tension, thus potentially enhancing pathogen killing by the innate immune system [20]. For some patients with sepsis, oxygen delivery to the tissues may be impaired. In such patients, liberal provision of oxygen might be of particular value.

To detect an effect on 90-day mortality with oxygen therapy of the magnitude suggested by point estimates of treatment effect in our study and assuming a control mortality rate of $36.2 \%$, a sample size of 1884 would be required for a trial with $90 \%$ power at an alpha of 0.05 . A more conservative approach of specifying an effect size of half of the effect observed in this analysis gives a sample size of 7744. Such sample size calculations, which are derived from a high-quality multicenter randomized controlled trial with high internal validity and a low risk of bias conducted in 21 ICUs provide a robust foundation on which to conduct further work.
Despite a plausible basis for harm with conservative oxygen therapy in patients with sepsis, it is important to emphasize that our current analysis was post hoc and not designed to establish a mortality difference. Our analysis does not rule out the possibility that conservative use of oxygen in patients with sepsis results in either clinically important benefit or harm. Our study has additional limitations. As we have highlighted, this was a post hoc analysis; however, it was hypothesis-driven, rather than data-driven and is highly relevant to clinicians, because sepsis is a common disease in ICU practice [1]. The ICU-ROX data that were used to define sepsis were collected at baseline; however, the subcodes for infection obtained from the Adult Patient Database were not collected specifically for the trial and may not truly be baseline data. Although we did not prospectively identify patients whether or not patients had the requisite organ dysfunction to meet sepsis criteria, we used registry data to confirm that the vast majority fulfilled the contemporary definition of sepsis [12] within $24 \mathrm{~h}$ of ICU admission. Some patients who were not identified as having an infection-related admission diagnosis may still have had sepsis at baseline or developed it in the ICU. We did not collect information related to oxygen delivery such as lactate and central venous oxygen saturations or information on the use of antibiotics or methods of source control. We did not collect oxygen-related data beyond 
Table 2 Primary outcome and key secondary outcomes

\begin{tabular}{|c|c|c|c|c|}
\hline \multirow{3}{*}{$\begin{array}{l}\text { Primary outcome } \\
\text { and key secondary outcomes }\end{array}$} & \multirow{3}{*}{$\begin{array}{l}\text { Conservative } \\
\text { oxygen }(n=130)\end{array}$} & \multirow[t]{3}{*}{ Usual oxygen $(n=121)$} & \multicolumn{2}{|l|}{ Estimate $^{a}(95 \% \mathrm{Cl})$} \\
\hline & & & \multicolumn{2}{|l|}{ Odds ratio; $P$ value } \\
\hline & & & Unadjusted & Adjusted $^{b}$ \\
\hline 90-day mortality, n/N (\%) & $47 / 130(36.2 \%)$ & $35 / 120(29.2 \%)$ & $1.38(0.81-2.34) ; P=0.24$ & $1.29(0.73-2.3) ; P=0.38$ \\
\hline 180-day mortality, n/N (\%) & $47 / 130(36.2 \%)$ & $39 / 118(33.1 \%)$ & $1.16(0.69-1.96) ; P=0.58$ & $1.02(0.57-1.82) ; P=0.94$ \\
\hline Died in ICU, $n / N(\%)$ & $34 / 119(28.6 \%)$ & 22/115 (19.1\%) & $1.69(0.92-3.12) ; P=0.09$ & $1.6(0.83-3.09) ; P=0.16$ \\
\hline \multirow[t]{2}{*}{ Died in hospital, n/N (\%) } & $43 / 130(33.1 \%)$ & $31 / 121(25.6 \%)$ & $1.43(0.83-2.48) ; P=0.2$ & $1.4(0.77-2.53) ; P=0.27$ \\
\hline & & & Difference in Medians ${ }^{\ddagger}$ & $P$ value \\
\hline ICU length of stay (days), median (IQR) & $6.1[3-13.3]$ & $5.7[3.1-9.6]$ & $0.3[-1.6$ to 2.1$]$ & 0.53 \\
\hline Hospital length of stay (days), median (IQR) & $15[6.9-26.7]$ & $13.1[8.0-26.4]$ & $1.9[-2.7$ to 6.5$]$ & 0.99 \\
\hline Vasopressor-free days, median (IQR) & $22[0-26]$ & $24.0[6-26]$ & $0.0[-0.9$ to 0.9$]$ & 0.16 \\
\hline \multirow[t]{2}{*}{ Ventilator-free days, median (IQR) } & $19.3[0-26.2]$ & $22.9[0-25.9]$ & $-3.5[-9.5$ to 2.6$]$ & 0.26 \\
\hline & & & Odds ratio (unadjusted) & $P$ value \\
\hline Patients receiving RRT in ICU, n/N (\%) & $48 / 130(36.9 \%)$ & $41 / 121(33.9 \%)$ & $1.14(0.68-1.92)$ & $P=0.62$ \\
\hline \multicolumn{2}{|l|}{ Cause-specific mortality, $n / N(\%)^{c}$} & & \multicolumn{2}{|l|}{$P$ value $=0.29$} \\
\hline Arrhythmia & $1 / 48(2.1 \%)$ & $0 / 39(0 \%)$ & & \\
\hline Brain damage & $4 / 48(8.3 \%)$ & $3 / 39(7.7 \%)$ & & \\
\hline Cardiogenic shock & $1 / 48(2.1 \%)$ & $6 / 39(15.4 \%)$ & & \\
\hline Distributive shock & $27 / 48(56.3 \%)$ & $17 / 39(43.6 \%)$ & & \\
\hline Hypovolemic shock & $0 / 48(0 \%)$ & $1 / 39(2.6 \%)$ & & \\
\hline Hypoxic respiratory failure & $12 / 48(25 \%)$ & $9 / 39(23.1 \%)$ & & \\
\hline Metabolic & $3 / 48(6.3 \%)$ & $2 / 39(5.1 \%)$ & & \\
\hline Other & $0 / 48(0 \%)$ & $1 / 39(2.6 \%)$ & & \\
\hline \multicolumn{5}{|c|}{ IQR Interquartile range, $C I$ confidence interval, $R R T$ renal replacement therapy } \\
\hline \multicolumn{5}{|c|}{$\begin{array}{l}\text { a The widths of the confidence intervals for secondary analyses have not been adjusted for multiplicity and the intervals should not be used to infer definite } \\
\text { differences between the groups }\end{array}$} \\
\hline \multicolumn{5}{|c|}{ b Adjusted for age, gender, site, and APACHE II score } \\
\hline \multicolumn{5}{|c|}{ c Includes one patient in the conservative oxygen group who died after 180-day } \\
\hline
\end{tabular}

day 28. Although the difference in time-weighted mean $\mathrm{PaO}_{2}$ between treatment groups was not large, we still observed substantial and statistically significant separation between treatment groups in our trial in terms of a number of metrics of oxygen exposure, including a substantially higher number of hours with $\mathrm{SpO}_{2} \geq 97 \%$ among patients assigned to usual oxygen. The clinical relevance of the difference in oxygen exposure between groups that we observed can only be established through the conduct of high-quality clinical trials with patientcentered end points such as mortality. If the magnitude of mortality treatment effect suggested by the point estimates observed in our trial turned out be the true effect, then the magnitude of separation in oxygen exposure we observed would clearly be clinically important. We submit that investigation of oxygen regimens should be added to the list of recently described priorities for research in sepsis and septic shock [21].

In conclusion, in this post hoc analysis of patients with sepsis enrolled in ICU-ROX, conservative oxygen therapy did not result in a statistically significantly reduction in mortality compared with usual oxygen. However, the data provided in this analysis can help guide the design, statistical powering, and conduct of future trials of this intervention in sepsis. 


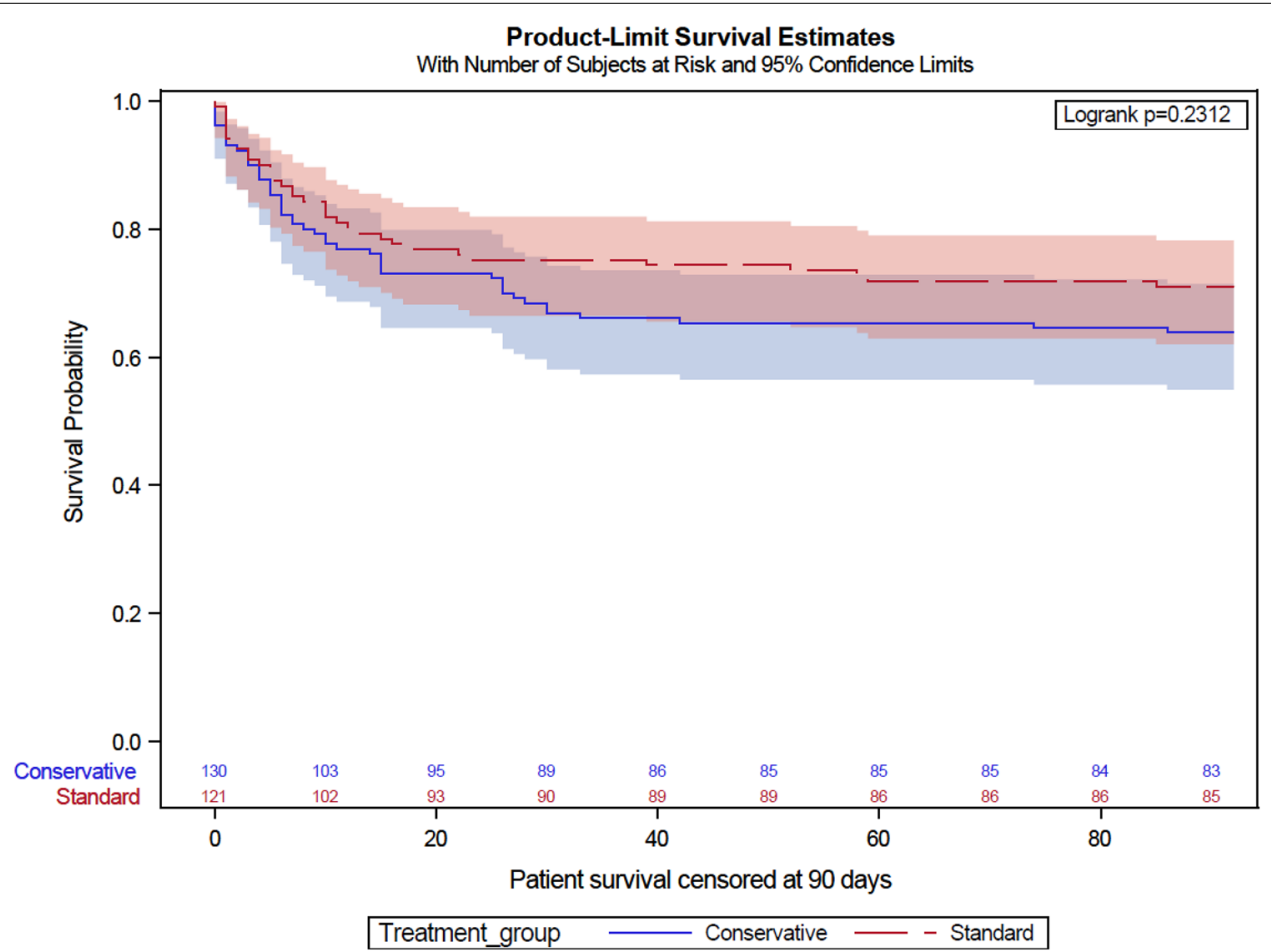

Fig. 3 Kaplan-Meier estimates of the probability of survival. *The number of observations is shown by treatment group on the horizontal axis. The hazard ratio is 0.8 [( $95 \% \mathrm{Cl} 0.5-1.3), P=0.40$ adjusted hazard ratio; 0.9 (95\% Cl 0.6-1.4); $P=0.78$ ]. Adjusted hazard ratios incorporate adjustment for age, gender, and APACHE II score, with patients nested in site and site treated as a random variable

\section{Electronic supplementary material}

The online version of this article (https://doi.org/10.1007/s00134-019-05857-x) contains supplementary material, which is available to authorized users.

\section{Author details}

${ }^{1}$ Medical Research Institute of New Zealand, Wellington, New Zealand. ${ }^{2}$ Intensive Care Unit, Wellington Regional Hospital, Private Bag 7902, Wellington South, New Zealand. ${ }^{3}$ Australian and New Zealand Intensive Care Research Centre, Monash University, Melbourne, VIC, Australia. ${ }^{4}$ Intensive Care Unit, Austin Hospital, Heidelberg, VIC, Australia. ${ }^{5}$ University of Melbourne, Parkville, VIC, Australia. ${ }^{6}$ Intensive Care Unit, Royal Melbourne Hospital, Parkville, VIC, Australia. ${ }^{7}$ Division of Critical Care and Trauma, The George Institute for Global Health, Sydney, NSW, Australia. ${ }^{8}$ Malcolm Fisher Department of Intensive Care Medicine, Royal North Shore Hospital, St Leonards, NSW, Australia. ${ }^{9}$ Intensive Care Unit, Hawkes Bay Hospital, Hastings, New Zealand. ${ }^{\circ}$ Intensive Care Unit, Fiona Stanley Hospital, Murdoch, WA, Australia. ${ }^{11}$ Department of Critical Care Medicine, Auckland City Hospital, Auckland, New Zealand. ${ }^{12}$ Cardiothoracic and Vascular Intensive Care Unit, Auckland City Hospital, Auckland, New Zealand. ${ }^{13}$ Intensive Care Unit, John Hunter Hospital, New Lambton Heights, NSW, Australia. ${ }^{14}$ School of Medicine and Public Health, University of Newcastle, Newcastle, Australia.

\section{Funding}

Funded by the New Zealand Health Research Council (Grant No. >16-014).

\section{Compliance with ethical standards}

\section{Conflicts of interest}

The authors report no conflicts of interest.

\section{Publisher's Note}

Springer Nature remains neutral with regard to jurisdictional claims in published maps and institutional affiliations.

Received: 15 October 2019 Accepted: 5 November 2019 Published online: 20 November 2019

\section{References}

1. Kaukonen KM, Bailey M, Suzuki S, Pilcher D, Bellomo R (2014) Mortality related to severe sepsis and septic shock among critically ill patients in Australia and New Zealand, 2000-2012. JAMA 311:1308-1316

2. Liu V, Escobar GJ, Greene JD, Soule J, Whippy A, Angus DC, I washyna TJ (2014) Hospital deaths in patients with sepsis from two independent cohorts. JAMA 312:90-92

3. Fleischmann C, Scherag A, Adhikari NK, Hartog CS, Tsaganos T, Schlattmann P, Angus DC, Reinhart K, International Forum of Acute Care T (2016) Assessment of global incidence and mortality of hospital-treated sepsis. Current estimates and limitations. Am J Respir Crit Care Med 193:259-272

4. Thompson K, Taylor C, Jan S, Li Q, Hammond N, Myburgh J, Saxena M, Venkatesh B, Finfer S (2018) Health-related outcomes of critically ill patients with and without sepsis. Intensive Care Med 44:1249-1257

5. Girardis M, Alhazzani W, Rasmussen BS (2019) What's new in oxygen therapy? Intensive Care Med 45:1009-1011

6. Chu DK, Kim LH, Young PJ, Zamiri N, Almenawer SA, Jaeschke R, Szczeklik W, Schunemann HJ, Neary JD, Alhazzani W (2018) Mortality and morbidity in acutely ill adults treated with liberal versus conservative oxygen therapy (IOTA): a systematic review and meta-analysis. Lancet 391:1693-1705

7. https://clinicaltrials.gov/ct2/show/NCT02378545. Accessed 14 Oct 2019 
8. Asfar P, Schortgen F, Boisrame-Helms J, Charpentier J, Guerot E, Megarbane B, Grimaldi D, Grelon F, Anguel N, Lasocki S, Henry-Lagarrigue M, Gonzalez F, Legay F, Guitton C, Schenck M, Doise JM, Devaquet J, Van Der Linden T, Chatellier D, Rigaud JP, Dellamonica J, Tamion F, Meziani F, Mercat A, Dreyfuss D, Seegers V, Radermacher P, Investigators HS, network $\operatorname{Rr}(2017)$ Hyperoxia and hypertonic saline in patients with septic shock (HYPERS2S): a two-by-two factorial, multicentre, randomised, clinical trial. Lancet Respir Med 5:180-190

9. Deane A, Eastwood G, Finfer S, Freebairn R, King V, Linke N, Litton E, McArthur C, McGuinness S, Panwar R, Young P. Conservative Oxygen Therapyduring Mechanical Ventilation in the ICU. N Engl J Med. 2019. https://doi.org/10.1056/NEJMoa1903297.

10. Moller MH, Alhazzani W, Shankar-Hari M (2019) Focus on sepsis. Intensive Care Med 45:1459-1461

11. Mackle DM, Bailey MJ, Beasley RW, Bellomo R, Bennett VL, Deane AM, Eastwood GM, Finfer S, Freebairn RC, Litton E, Linke NJ, McArthur CJ, McGuinness SP, Panwar R, Young PJ, Australian, New Zealand Intensive Care Society Clinical Trials G (2018) Protocol summary and statistical analysis plan for the intensive care unit randomised trial comparing two approaches to oxygen therapy (ICU-ROX). Crit Care Resusc 20:22-32

12. Singer M, Deutschman CS, Seymour CW, Shankar-Hari M, Annane D, Bauer M, Bellomo R, Bernard GR, Chiche JD, Coopersmith CM, Hotchkiss RS, Levy MM, Marshall JC, Martin GS, Opal SM, Rubenfeld GD, van der Poll T, Vincent JL, Angus DC (2016) The third international consensus definitions for sepsis and septic shock (Sepsis-3). JAMA 315:801-810

13. Raith EP, Udy AA, Bailey M, McGloughlin S, Maclsaac C, Bellomo R, Pilcher DV, Australian, New Zealand Intensive Care Society Centre for O, Resource E (2017) Prognostic Accuracy of the SOFA Score, SIRS Criteria, and qSOFA Score for In-hospital mortality among adults with suspected infection admitted to the intensive care unit. JAMA 317:290-300
14. Ridgeon E, Bellomo R, Myburgh J, Saxena M, Weatherall M, Jahan R, Arawwawala D, Bell S, Butt W, Camsooksai J, Carle C, Cheng A, Cirstea E, Cohen J, Cranshaw J, Delaney A, Eastwood G, Eliott S, Franke U, Gantner D, Green C, Howard-Griffin R, Inskip D, Litton E, Maclsaac C, McCairn A, Mahambrey T, Moondi P, Newby L, O'Connor S, Pegg C, Pope A, Reschreiter H, Richards B, Robertson M, Rodgers H, Shehabi Y, Smith I, Smith J, Smith N, Tilsley A, Whitehead C, Willett E, Wong K, Woodford C, Wright S, Young P (2016) Validation of a classification system for causes of death in critical care: an assessment of inter-rater reliability. Crit Care Resusc 18:50-54

15. Schoenfeld DA, Bernard GR, Network A (2002) Statistical evaluation of ventilator-free days as an efficacy measure in clinical trials of treatments for acute respiratory distress syndrome. Crit Care Med 30:1772-1777

16. Koenker RDO (1993) Computing regression quantiles. Appl Stat 43:410-414

17. Knighton DR, Hunt TK, Scheuenstuhl H, Halliday BJ, Werb Z, Banda MJ (1983) Oxygen tension regulates the expression of angiogenesis factor by macrophages. Science 221:1283-1285

18. Rodriguez PG, Felix FN, Woodley DT, Shim EK (2008) The role of oxygen in wound healing: a review of the literature. Dermatol Surg 34:1159-1169

19. Hays RC, Mandell GL (1974) PO2, pH, and redox potential of experimental abscesses. Proc Soc Exp Biol Med 147:29-30

20. Allen DB, Maguire JJ, Mahdavian M, Wicke C, Marcocci L, Scheuenstuhl H, Chang M, Le AX, Hopf HW, Hunt TK (1997) Wound hypoxia and acidosis limit neutrophil bacterial killing mechanisms. Arch Surg 132:991-996

21. Coopersmith CM, De Backer D, Deutschman CS, Ferrer R, Lat I, Machado FR, Martin GS, Martin-Loeches I, Nunnally ME, Antonelli M, Evans LE, Hellman J, Jog S, Kesecioglu J, Levy MM, Rhodes A (2018) Surviving sepsis campaign: research priorities for sepsis and septic shock. Intensive Care Med 44:1400-1426 